\title{
ANALISIS CEMARAN MIKROBA PADA KUE BASAH DI PASAR BESAR KOTA PALANGKA
} RAYA

\author{
${ }^{1}$ Susi Novaryatiin, ${ }^{1}$ Dewi Sari Mulia \\ 1Dosen Pengajar Program Studi D-III Farmasi, Fakultas IImu Kesehatan, \\ Universitas Muhammadiyah Palangkaraya \\ Email : \\ susi_novaryatiin@yahoo.com \\ dewisarimulia@gmail.com
}

\begin{abstract}
ABSTRAK
Peraturan Menteri Kesehatan Republik Indonesia Nomor 1096 Tahun 2011 tentang Higiene Sanitasi Jasaboga menyebutkan bahwa makanan yang dikonsumsi manusia harus higienis, sehat, dan aman yaitu bebas dari cemaran fisika, cemaran kimia, dan cemaran biologi. Cemaran biologi atau mikroba dapat mencemari makanan

Kue basah merupakan makanan kecil yang biasa dijadikan alternatif cemilan. Kue basah terbuat dari bahan seperti tepung, air, telur, dan pemanis. Kue basah sering disebut juga kue jajanan pasar, karena memang banyak dijual di pasar-pasar, baik pasar besar maupun pasar malam. Berdasarkan pengamatan di Pasar Besar Kota Palangka Raya terdapat penjual kue basah yang lokasi penjualannya kurang bersih, kue yang dijual tidak tertutup, waktu pengolahan dan proses penjualan yang panjang sehingga ada kemungkinan kue basah yang dijual dilokasi tersebut tercemar oleh mikroba.

Penelitian ini bertujuan untuk mengetahui ada atau tidaknya cemaran bakteri pada kue basah, dan untuk mengetahui ada atau tidaknya angka kuman yang melebihi batas maksimum cemaran mikroba pada kue basah yang dijual di Jalan Jawa Pasar Besar Kota Palangka Raya.

Penelitian ini dilakukan di Laboratorium Mikrobiologi Fakultas IImu Kesehatan Universitas Muhammadiyah Palangkaraya.Kegiatan penelitian yang dilakukan adalah pengambilan sampel, pengenceran sampel, pembacaan hasil, dan perhitungan angka kuman. Sampel penelitian ini yaitu semua kue basah yang dijual secara terbuka atau tanpa kemasan oleh 7pedagang kue basah di Pasar Besar Kota Palangka Raya. Jumlah sampel penelitian sebanyak 25 kue basah. Metode perhitungan yang digunakan adalah Angka Lempeng Total $(\mathrm{ALT})$ yang dilakukan secara duplo.

Pada penelitian ini diketahui bahwa terdapat cemaran mikroba pada 19dari 25 sampel kue basah yang dijual di Pasar Besar Kota Palangka Raya, dan terdapat 2 sampel kue basah yang memiliki angka kuman melebihi batas maksimum cemaran mikroba pada kue basah yaitu sampel 13 dengan rata-rata angka kuman sebesar 3,1 × $10^{5} \mathrm{koloni} / \mathrm{g}$, dan sampel 15 dengan rata-rata angka kuman sebesar $9,5 \times 10^{5} \mathrm{koloni} / \mathrm{g}$.
\end{abstract}

Kata Kunci: angka kuman, TPC, kue basah, pemeriksaan mikrobiologi

\section{PENDAHULUAN}

Berdasarkan Undang-Undang

Nomor 36 Tahun 2009 tentang Kesehatan menyebutkan bahwa kesehatan adalah keadaan sejahtera dari badan, jiwa dan sosial yang memungkinkan setiap orang 
hidup produktif secara sosial dan ekonomis, dengan demikian kesehatan selain sebagai hak asasi manusia, kesehatan juga merupakan investasi. Kesehatan adalah keadaan sehat, baik secara fisik, mental, spiritual maupun sosial yang memungkinkan setiap orang untuk hidup produktif secara sosial dan ekonomis, agar kesehatan selalu terjaga maka hal yang harus dilakukan adalah menghindari makanan atau jajanan sembarangan dan makan-makanan bergizi serta rutin berolahraga.

Makanan menurut WHO (World Health Organization) yaitu semua substansi yang diperlukan tubuh, kecuali air dan obatobatan dan substansi-substansi yang diperlukan untuk pengobatan. Makanan merupakan salah satu faktor yang langsung berpengaruh terhadap kondisi kesehatan manusia. Pangan yang aman, bermutu dan bergizi dibutuhkan tubuh untuk menunjang aktivitas. Namun sebaliknya, pangan yang tidak memenuhi standar keamanan, mutu dan gizi akan membahayakan kesehatan tubuh. Oleh karena itu, pemilihan pangan sebelum dikonsumsi sangat penting agar terhindar dan produk pangan yang tidak memenuhi standar serta dapat membahayakan kesehatan (Muchtaridi, 2011).

Pada tahun 2003 ditemukan bahwa dari 18 kasus keracunan sebanyak 83,3\% diduga disebabkan oleh bakteri patogen.
Demikian pula pada tahun 2004 dan 2005, yaitu sebanyak $60 \%$ dari 41 kasus keracunan dan $72,2 \%$ dari53 kasus keracunan juga diduga karena adanya mikroorganisme, terutama bakteri patogen. Sementara itu, sisanya disebabkan oleh zat kimia dan lain-lain (tidak diketahui). Ternyata sebagian besar kasus keracunan makanan bersumber pada makanan siap santap yang diolah oleh industri jasa boga, sedangkan lainnya berasal dari pengolahan rumah tangga yang diolah untuk konsumsi massal (Irianto, 2013).

Salah satu jenis makanan yang diminati masyarakatadalah kue basah. Jika dalam pembuatan kue basah tersebut tidak menggunakan air yang bersih maka terdapat pemicu timbulnya penyakit yang berasal dari mikroba patogen. Mikroorganisme patogen ini akan berkembang biak didalam saluran pencernaan dan selanjutnya akan menyebabkan penyakit, misalnya penyakit perut seperti disentri, typus, dan diare.

Berdasarkan pengamatan di Pasar Besar Kota Palangka Raya terdapat penjual kue basah yang lokasi penjualannya kurang bersih, kue yang dijual tidak tertutup, waktu pengolahan dan proses penjualan yang panjang sehingga ada kemungkinan kue basah yang dijual di lokasi tersebut terkontaminasi bakteri. Berdasarkan latar belakang diatas, maka perlu dilakukan penelitian terhadap analisis cemaran 
Analisis Cemaran Mikroba pada Kue Basah di Pasar Besar Kota Palangka Raya

mikroba pada kue basah di Pasar Besar Kota Palangka Raya.

Penelitian ini bertujuan untuk mengetahui ada atau tidaknya cemaran bakteri pada kue basah, dan untuk mengetahui ada atau tidaknya angka kuman yang melebihi batas maksimum cemaran mikroba pada kue basah yang dijual di Jalan Jawa Pasar Besar Kota Palangka Raya.

\section{METODE PENELITIAN}

Penelitian ini dilakukan di Laboratorium Mikrobiologi Fakultas IImu Kesehatan Universitas Muhammadiyah Palangkaraya. Penelitian dilaksanakan selama 3 (tiga) bulan.Kegiatan penelitian yang dilakukan adalah pengambilan sampel, pengenceran sampel, pembacaan hasil, dan perhitungan angka kuman.

\section{Sampel Penelitian}

Sampel penelitian adalah semua kue basah yang dijual secara terbuka (tanpa kemasan) oleh 7pedagang kue basah di Pasar Besar Kota Palangka Raya, tepatnya di Jalan Jawa dan Jalan Sumatera. Jumlah sampel pada penelitian ini adalah sebanyak 25 macam kue basah yang dijual secara terbuka (tanpa kemasan).

\section{Pengenceran Sampel(Lay,1994)}

Sebanyak 20 gram sampel ditimbang dilarutkandengan $180 \mathrm{~mL}$ aquadest, lalu dikocok hingga homogen.

Sebanyak 5 tabung reaksi steril disusun pada rak tabung dan secara berurutan diberi tanda $10^{-1}, 10^{-2}, 10^{3}, 10^{-4}$, $10^{-5}$. Tabung reaksi ke-2 sampai dengan ke5 , diisi dengan $9 \mathrm{~mL}$ aquadest.

$10 \mathrm{~mL}$ sampel dimasukkan pada tabung reaksi ke-1. Lalu $1 \mathrm{~mL}$ sampel dari tabung ke-1 dipindahkan ke dalam tabung ke-2 dengan pipet ukur steril, cairan dibuat sampai homogen. Dilanjutkan dengan memindahkan $1 \mathrm{~mL}$ sampel dari tabung ke2 ke dalam tabung ke-3 dengan pipet ukur steril.Demikian seterusnya dilakukan sampai tabung ke-5. Pengenceran yang diperoleh pada tabung adalah 10-1, 10-2, 103 , $10^{-4}, 10^{-5}$ sesuai dengan kode pengenceran yang telah tercantum sebelumnya.

Dari tabung reaksi $10^{-1}$ dengan menggunakan pipet steril, diambil $1 \mathrm{~mL}$ masukkan ke dalam masing-masing cawan petri steril, sesuai dengan kode pengenceran yang sama.Masing-masing cawan petri dituang mediaPlate Count Agar(PCA) cair yang telah disterilisasi sebanyak 15-20 mL. Masing-masing cawan petri digoyang perlahan-lahan hingga tercampur merata dan dibiarkan hingga dingin dan membeku, lalu diinkubasi pada 
suhu $37^{\circ} \mathrm{C}$ selama $1 \times 24$ jam dalam keadaan terbalik.

Khusus kontrol negatif, dibuat dengan memasukkan $1 \mathrm{~mL}$ aquadest steril ke dalam cawan petri "Kontrol" dan dituang mediaPlate Count Agar(PCA) cair sebanyak $15-20 \mathrm{~mL}$.

\section{Pembacaan Hasil (Lay, 1994)}

Pembacaan dilakukan setelah 1 × 24 jam dengan cara menghitung jumlah koloni yang tumbuh pada tiap-tiap cawan petri.

Pembacaan hasil dilakukan dengan menghitung jumlah koloni yang tumbuh pada tiap cawan petri. Koloni yang bergabung menjadi satu atau membentuk satu deretan/koloni dihitung sebagai 1 koloni kuman.

Pemeriksaan harus diulang apabila jumlah koloni pada cawan petri kontrol lebih besar dari 10, karena sterilisasi dianggap kurang baik

\section{Perhitungan Angka Kuman (Lay, 1994)}

Perhitungan hanya dilakukan pada cawan petri yang menghasilkan jumlah koloni antara 30-300, serta jumlah koloni pada cawan petri kontrol lebih kecil dari 10. Jumlah koloni pada masing-masing cawan petri ini harus terlebih dahulu dikurangi dengan jumlah koloni pada cawan petri kontrol.

\section{HASIL DAN PEMBAHASAN}

Pada penelitian ini dilakukan analisis cemaran mikroba dengan Uji Angka Lempeng Total (ALT) pada makanan yaitu kue basah. Uji ALT adalah salah satu metode yang digunakan untuk mengetahui jumlah cemaran mikroba dalam suatu produk. Tujuan dilakukannya penelitian ini adalah untuk mengetahui angka kuman yang mencemari kue basah, hal ini perlu dilakukan untuk mengetahui sampai seberapa jauh kue basah tersebut tercemar oleh mikroba, sehingga dapat diketahui kualitas mikrobiologi dari kue basah tersebut.

Uji ALT dilakukan pada 25 sampel kue basah yang dijual oleh 7 penjual kue basah yang berbeda yaitu penjual 1 (4 kue basah), penjual 2 (4 kue basah), penjual 3 (3 kue basah), penjual 4 (4 kue basah), penjual 5 (4 kue basah), penjual 6 (3 kue basah), dan penjual 7 (3 kue basah) (Tabel 1).

Tabel 1.Data Sampel Kue Basah

\begin{tabular}{clc}
\hline Penjual & Sampel Kue Basah & Kode Sampel \\
\hline \multirow{2}{*}{1} & Apam Kuning & 1 \\
\cline { 2 - 3 } & Bingka & 2 \\
\hline
\end{tabular}


Analisis Cemaran Mikroba pada Kue Basah di Pasar Besar Kota Palangka Raya

\begin{tabular}{lll}
\hline & Apam Putih & 3 \\
\cline { 2 - 3 } 2 & Cincin & 4 \\
\cline { 2 - 3 } & Cincin & 5 \\
\cline { 2 - 3 } & Apam Putih & 6 \\
\cline { 2 - 3 } & Apam Kuning & 7 \\
\cline { 2 - 3 } & Kalaman Ayam & 8 \\
\hline \multirow{2}{*}{4} & Cucur & 9 \\
\cline { 2 - 3 } & Cincin & 10 \\
\cline { 2 - 3 } & Bingka & 11 \\
\cline { 2 - 3 } & Bingka & 12 \\
\cline { 2 - 3 } & Cincin & 13 \\
\cline { 2 - 3 } & Apam Kuning & 14 \\
\hline \multirow{2}{*}{5} & Apam Peranggi & 15 \\
\cline { 2 - 3 } & Apam Peranggi & 16 \\
\cline { 2 - 3 } & Apam Putih & 17 \\
\cline { 2 - 3 } & Roti Pisang & 18 \\
\cline { 2 - 3 } & Roti Manis & 19 \\
\hline 6 & Apam Kukus & 20 \\
\cline { 2 - 3 } & Bingka & 21 \\
\cline { 2 - 3 } & Singkong Goreng & 22 \\
\hline 7 & Cucur & 25 \\
\cline { 2 - 3 } & Cincin & \\
\cline { 2 - 3 } & Onde-onde & 23 \\
\hline & & \\
\hline
\end{tabular}

Sumber: Data Primer, 2017

Penelitian ini dilakukan dengan pengenceran terhadap sampel. Pengenceran ini bertujuan untuk mendapatkan koloni bakteri dengan jumlah antara 30-300 sehingga mempermudah perhitungan koloni. Jika tidak dilakukan pengenceran, maka akan dihasilkan pertumbuhan koloni bakteri yang pekat pada media agar sehingga perhitungan koloni sulit dilakukan. Pada penelitian ini dilakukan pengulangan sebanyak dua kali, hal ini bertujuan untuk mendapatkan hasil penelitian yang akurat.
Media yang digunakan pada penelitian ini adalah mediaPlate Count Agar (PCA), media tersebut digunakan sebagai medium untuk mikroba aerobik dengan inokulasi di atas permukaan. Media PCA adalah media universal yang digunakan untuk menghitung jumlah bakteri dari spesimen tertentu dengan metode Total Plate Count (TPC) / Angka Lempeng Total (ALT). Media ini mengandung glukosa dan ekstrak ragi yang digunakan untuk menumbuhkan semua jenis bakteri. Media PCA mengandung nutrisi yang 
didapatkan dari trypton, vitamin dari ekstrak ragi, dan glukosa sebagai sumber energi bakteri (Arianda, 2016).

Pada penelitian ini diperlukan kontrol negatif untuk mengetahui bahwa media yang digunakan tidak terkontaminasi oleh mikroorganisme, sehingga pada saat pengamatan hasil penelitian, hasil positif cemaran mikroba benar-benar dari sampel, bukan dari media atau cara pengerjaan yang kurang steril.

Berdasarkan data hasil uji ALT, dapat dilakukan perhitungan angka kuman untuk mengetahui jumlah cemaran mikroba pada sampel. Perhitungan hanya dilakukan pada cawan petri yang menghasilkan jumlah koloni antara 30-300 serta jumlah koloni pada cawan petri kontrol <10. Jumlah koloni pada masing-masing cawan petri ini harus terlebih dahulu dikurangi dengan jumlah koloni pada cawan petri kontrol (Lay, 1994). Berikut merupakan data hasil ujiALT dan perhitungan angka kuman pada kue basah.

Tabel 2.Data Hasil Uji ALT dan Perhitungan Angka Kuman pada Kue Basah

\begin{tabular}{|c|c|c|c|c|c|c|c|c|c|}
\hline \multirow{2}{*}{$\begin{array}{c}\text { Kode } \\
\text { Sampel }\end{array}$} & \multirow[t]{2}{*}{ Pengulangan } & \multicolumn{6}{|c|}{ Hasil Penelitian 24 Jam } & \multirow{2}{*}{$\begin{array}{c}\text { Angka } \\
\text { kuman } \\
\text { (koloni/g) }\end{array}$} & \multirow{2}{*}{$\begin{array}{c}\text { Rata-rata } \\
\text { angka } \\
\text { kuman } \\
\text { (koloni/g) }\end{array}$} \\
\hline & & Kontrol & $10^{-1}$ & $10^{-2}$ & $10^{-3}$ & $10^{-4}$ & $10^{-5}$ & & \\
\hline \multirow[t]{2}{*}{1} & (1) & 0 & 457 & 40 & 1 & 1 & - & $4,0 \times 10^{3}$ & $4,0 \times 10^{3}$ \\
\hline & (2) & 0 & 400 & 40 & 3 & 2 & - & $4,0 \times 10^{3}$ & \\
\hline \multirow[t]{2}{*}{2} & (1) & 0 & 200 & 80 & 27 & 11 & 5 & $5,0 \times 10^{3}$ & $4,1 \times 10^{3}$ \\
\hline & (2) & 0 & 400 & 33 & 8 & 1 & - & $3,3 \times 10^{3}$ & \\
\hline \multirow[t]{2}{*}{3} & (1) & 0 & 440 & 3 & 2 & 1 & - & Negatif & $2,4 \times 10^{4}$ \\
\hline & (2) & 1 & 940 & 90 & 40 & 15 & 5 & $2,4 \times 10^{4}$ & \\
\hline \multirow[t]{2}{*}{4} & (1) & 1 & 23 & 4 & 1 & - & - & Negatif & $1,0 \times 10^{2}$ \\
\hline & (2) & 0 & 102 & 11 & 7 & 2 & 1 & $1,0 \times 10^{2}$ & \\
\hline \multirow[t]{2}{*}{5} & (1) & 3 & 60 & 11 & 5 & 3 & 2 & $5,7 \times 10^{2}$ & $5,4 \times 10^{2}$ \\
\hline & (2) & 0 & 52 & 4 & 3 & 2 & 2 & $5,2 \times 10^{2}$ & \\
\hline \multirow[t]{2}{*}{6} & (1) & 0 & 17 & 4 & 3 & 1 & 1 & Negatif & Negatif \\
\hline & (2) & 1 & 20 & 3 & 2 & 2 & 1 & Negatif & \\
\hline \multirow[t]{2}{*}{7} & (1) & 0 & 800 & 45 & 14 & 8 & 3 & $4,5 \times 10^{3}$ & $6,2 \times 10^{3}$ \\
\hline & (2) & 0 & 403 & 80 & 19 & 8 & 7 & $8,0 \times 10^{3}$ & \\
\hline \multirow[t]{2}{*}{8} & (1) & 2 & 500 & 7 & 1 & 1 & 1 & Negatif & Negatif \\
\hline & (2) & 3 & 407 & 306 & 4 & 3 & 1 & Negatif & \\
\hline \multirow[t]{2}{*}{9} & (1) & 3 & 1 & 1 & 7 & 2 & 2 & Negatif & Negatif \\
\hline & (2) & 4 & 3 & 4 & 12 & 2 & 2 & Negatif & \\
\hline \multirow[t]{2}{*}{10} & (1) & 1 & 3 & 16 & 5 & 1 & 20 & Negatif & $2,5 \times 10^{4}$ \\
\hline & (2) & 2 & 408 & 98 & 43 & 17 & 9 & $2,5 \times 10^{4}$ & \\
\hline
\end{tabular}


Analisis Cemaran Mikroba pada Kue Basah di Pasar Besar Kota Palangka Raya

\begin{tabular}{|c|c|c|c|c|c|c|c|c|c|}
\hline \multirow[t]{2}{*}{11} & (1) & 0 & - & 44 & 2 & 2 & 1 & $4,4 \times 10^{3}$ & \multirow[t]{2}{*}{$2,7 \times 10^{4}$} \\
\hline & (2) & 2 & - & 4 & 105 & 16 & 27 & $1,0 \times 10^{5}$ & \\
\hline \multirow[t]{2}{*}{12} & (1) & 3 & 540 & 130 & 40 & 15 & 11 & $2,5 \times 10^{3}$ & \multirow[t]{2}{*}{$2,6 \times 10^{3}$} \\
\hline & (2) & 2 & 720 & 120 & 47 & 21 & 10 & $2,8 \times 10^{4}$ & \\
\hline \multirow[t]{2}{*}{13} & (1) & 2 & 568 & 80 & 56 & 34 & 27 & $1,3 \times 10^{5}$ & \multirow[t]{2}{*}{$3,1 \times 10^{5}$} \\
\hline & (2) & 3 & 500 & 70 & 11 & 8 & 40 & $1,8 \times 10^{6}$ & \\
\hline \multirow[t]{2}{*}{14} & (1) & 5 & 503 & 31 & 17 & 10 & 39 & $1,7 \times 10^{6}$ & \multirow[t]{2}{*}{$5,7 \times 10^{4}$} \\
\hline & (2) & 5 & 45 & 27 & 15 & 15 & 11 & $4,0 \times 10^{2}$ & \\
\hline \multirow[t]{2}{*}{15} & (1) & 4 & 87 & 60 & 51 & 37 & 33 & $7,6 \times 10^{6}$ & \multirow[t]{2}{*}{$9,5 \times 10^{5}$} \\
\hline & (2) & 3 & 400 & 32 & 38 & 10 & 18 & $1,9 \times 10^{4}$ & \\
\hline \multirow[t]{2}{*}{16} & (1) & 0 & 362 & 112 & 37 & 2 & 1 & $2,4 \times 10^{4}$ & \multirow[t]{2}{*}{$3,0 \times 10^{4}$} \\
\hline & (2) & 0 & 480 & 236 & 47 & 5 & 2 & $7,0 \times 10^{4}$ & \\
\hline \multirow[t]{2}{*}{17} & (1) & 0 & 30 & 15 & 6 & 1 & 1 & $3,0 \times 10^{2}$ & \multirow[t]{2}{*}{$1,3 \times 10^{3}$} \\
\hline & (2) & 0 & 57 & 42 & 22 & 2 & 2 & $2,4 \times 10^{3}$ & \\
\hline \multirow[t]{2}{*}{18} & (1) & 0 & 42 & 35 & 11 & 9 & 1 & $2,0 \times 10^{3}$ & \multirow[t]{2}{*}{$2,0 \times 10^{3}$} \\
\hline & (2) & 0 & 24 & 15 & 13 & 11 & 0 & Negatif & \\
\hline \multirow[t]{2}{*}{19} & (1) & 0 & 212 & 150 & 60 & 13 & 12 & $2,6 \times 10^{4}$ & \multirow[t]{2}{*}{$1,3 \times 10^{4}$} \\
\hline & (2) & 0 & 37 & 13 & 9 & 8 & 7 & $3,7 \times 10^{2}$ & \\
\hline \multirow[t]{2}{*}{20} & (1) & 0 & 436 & 151 & 55 & 3 & 1 & $2,5 \times 10^{4}$ & \multirow[t]{2}{*}{$1,9 \times 10^{4}$} \\
\hline & (2) & 0 & 291 & 37 & 17 & 10 & 4 & $3,3 \times 10^{3}$ & \\
\hline \multirow[t]{2}{*}{21} & (1) & 0 & 240 & 35 & 2 & 1 & 1 & $3,0 \times 10^{3}$ & \multirow[t]{2}{*}{$2,5 \times 10^{3}$} \\
\hline & (2) & 0 & 211 & 27 & 6 & 2 & 1 & $2,1 \times 10^{3}$ & \\
\hline \multirow[t]{2}{*}{22} & (1) & 0 & 152 & 45 & 3 & 0 & 0 & $3,0 \times 10^{3}$ & \multirow[t]{2}{*}{$2,3 \times 10^{3}$} \\
\hline & (2) & 0 & 162 & 22 & 7 & 2 & 0 & $16 \times 10$ & \\
\hline \multirow[t]{2}{*}{23} & (1) & 0 & 22 & 13 & 5 & 2 & 0 & Negatif & \multirow[t]{2}{*}{ Negatif } \\
\hline & (2) & 0 & 19 & 16 & 5 & 4 & 3 & Negatif & \\
\hline \multirow[t]{2}{*}{24} & (1) & 0 & 13 & 9 & 4 & 1 & 0 & Negatif & \multirow[t]{2}{*}{ Negatif } \\
\hline & (2) & 0 & 18 & 14 & 5 & 2 & 1 & Negatif & \\
\hline \multirow[t]{2}{*}{25} & (1) & 0 & 25 & 10 & 6 & 5 & 2 & Negatif & Negatif \\
\hline & (2) & 0 & 28 & 18 & 10 & 5 & 3 & Negatif & \\
\hline
\end{tabular}

Sumber: Data Primer, 2017

Berdasarkan data hasil penelitian, didapatkan bahwa 19 dari 25 sampel yang diuji positif tercemar mikroba. Sampel yang positif tersebut antara lain sampel 1 dengan rata-rata angka kuman $4,0 \times 10^{3} \mathrm{koloni} / \mathrm{g}$; sampel 2 dengan rata-rata angka kuman 4,1 x $10^{3} \mathrm{koloni} / \mathrm{g}$; sampel 3 dengan rata-rata angka kuman 2,4 x 104koloni/g; sampel 4 dengan rata-rata angka kuman $1,0 \quad x$ 10²koloni/g; sampel 5 dengan rata-rata angka kuman $5,4 \times 10^{2} \mathrm{koloni} / \mathrm{g}$; sampel 7 dengan rata-rata angka kuman 6,2 x 103koloni/g; sampel 10 dengan rata-rata angka kuman 2,5 x $10^{4} \mathrm{koloni} / \mathrm{g}$; sampel 11 dengan rata-rata angka kuman $2,7 \times 10^{4} \mathrm{koloni} / \mathrm{g}$; sampel 12 dengan rata-rata angka kuman $2,6 \mathrm{x}$ 
$10^{3} \mathrm{koloni} / \mathrm{g}$; sampel 13 dengan rata-rata angka kuman 3,1 x $10^{5} \mathrm{koloni} / \mathrm{g}$; sampel 14 dengan rata-rata angka kuman $5,7 \mathrm{x}$ $10^{4} \mathrm{koloni} / \mathrm{g}$; sampel 15 dengan rata-rata angka kuman 9,5 x $10^{5} \mathrm{koloni} / \mathrm{g}$; sampel 16 dengan rata-rata angka kuman $3,0 \mathrm{x}$ $10^{4} \mathrm{koloni} / \mathrm{g}$; sampel 17 dengan rata-rata angka kuman $1,3 \times 10^{3} \mathrm{koloni} / \mathrm{g} ;$ sampel 18 dengan rata-rata angka kuman $2,0 \mathrm{x}$ $10^{3} \mathrm{koloni} / \mathrm{g} ;$ sampel 19 dengan rata-rata angka kuman $1,3 \times 10^{4} \mathrm{koloni} / \mathrm{g}$; sampel 20 dengan rata-rata angka kuman $1,9 \times 10^{4}$ koloni/g; sampel 21 dengan rata-rata angka kuman $2,5 \times 10^{3}$ koloni/g; dan sampel 22 dengan rata-rata angka kuman $2,3 \times 10^{3}$ koloni/g. Sedangkan sampel yang negatif tercemar bakteri yaitu sampel 6, 8, 9, 23, 24, dan 25.

Badan Pengawas Obat dan Makanan Republik Indonesia (BPOM RI) (2012) menetapkan bahwa batas maksimum cemaran mikroba pada kue basah dengan

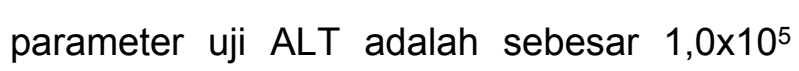
koloni/g. Berdasarkan pedoman yang ditetapkan oleh BPOM RI tersebut, maka 2 dari 19 sampel yang positif tercemar mikroba dapat dinyatakan tidak memenuhi standar untuk dikonsumsi karena memiliki angka kuman di atas $1,0 \times 10^{5} \mathrm{koloni} / \mathrm{g}$. Kedua sampel yang melebihi batas maksimum tersebut adalah sampel 13 (kue cincin, penjual 4) dengan dengan rata-rata angka kuman sebesar 3,1 x 105 koloni $/ g$, dan sampel 15 (kue apam peranggi, penjual 4) dengan rata-rata angka kuman sebesar 9,5 x $10^{5} \mathrm{koloni} / \mathrm{g}$.

Adanya cemaran mikroba pada sampel kue basah dapat terjadi karena berbagai faktor. Salah satu penyebabnya adalah kurangnya penerapan higiene dan sanitasi makanan oleh penjual kue basah seperti lokasi penjualan yang berada di pinggir jalan raya, dan banyak terpapar debu asap kendaraan, sehingga berpotensi menjadi sumber pencemaran bakteri patogen. Kondisi lingkungan yang kotor dan tidak terjaga sanitasinya dapat menyebabkan makanan tercemar mikroba. Selain itu, kurangnya kebersihan peralatan yang digunakan seperti wadah untuk meletakkan kue basah, dan alat penjepit yang digunakan untuk mengambil kue basah, juga dapat menjadi salah satu faktor penyebab adanya cemaran mikroba pada kue basah.

\section{KESIMPULAN}

Kesimpulan yang didapat dari penelitian ini adalah:

1. Terdapat cemaran mikroba pada 19 dari 25 sampel kue basah yang dijual di Pasar Besar Kota Palangka Raya.

2. 2 sampel kue basah memiliki angka kuman melebihi batas maksimum cemaran mikroba pada kue basah yaitu sampel 13 dengan rata-rata angka kuman sebesar $3,1 \times 10^{5} \mathrm{koloni} / \mathrm{g}$, dan sampel 15 dengan rata-rata angka kuman sebesar $9,5 \times 10^{5}$ koloni/g. 


\section{DAFTAR PUSTAKA}

1. Arianda, D. 2016. Buku Saku Bakteriologi. AM-Publishing.

4. Kesehatan Nomor 36 Tahun 2009 tentang Kesehatan. Jakarta.

5. Irianto, K. 2013. Mikrobiologi Medis. Bandung: Alfabeta.

6. Kementerian Kesehatan Republik Indonesia. 2011. Peraturan Menteri Kesehatan Republik Indonesia Nomor 1096 Tahun 2011 tentang Higiene Sanitasi Jasaboga. Jakarta.

7. Lay, B.W. 1994. Analisis Mikroba di Laboratorium. Jakarta: Raja Grafindo.

8. Muchtaridi. 2011. Panduan Penyiapan

Pangan Sehat Untuk Semua. Jakarta:

Kencan
2. Badan Pengawas Obat dan Makanan Republik Indonesia. 2012. Pedoman Penyelenggaraan Bulan Keamanan Pangan Nasional . Jakarta.

3. Departemen Kesehatan Republik Indonesia. 2009. Undang-Undang 